\title{
An Absurd Consequence of Stanford's New Induction over the History of Science: A reply to Sterpetti
}

Moti Mizrahi

Florida Institute of Technology

Forthcoming in Axiomathes

\begin{abstract}
In this paper, I respond to Fabio Sterpetti's (2018) attempt to defend Kyle P.
Stanford's Problem of Unconceived Alternatives (PUA) and his New Induction over the History of Science (NIS) from my reductio argument outlined in Mizrahi (2016a). I discuss what I take to be the ways in which Sterpetti has misconstrued my argument against Stanford's NIS, in particular, that it is a reductio, not a dilemma, as Sterpetti erroneously thinks. I argue that antirealists who endorse Stanford's NIS still face an absurd consequence of this argument, namely, that they should not believe their own brand of scientific antirealism.
\end{abstract}

Keywords: New Induction; Problem of Unconceived Alternatives; Problem of Unconceived Objections; Scientific Antirealism; Scientific Realism

\section{Introduction}

According to Kyle P. Stanford (2006, p. 19), "the history of scientific inquiry itself offers a straightforward rationale for thinking that there typically are alternatives to our best theories equally well confirmed by the evidence, even when we are unable to conceive of them at the time." Stanford (2001, p. S9) calls this the Problem of Unconceived Alternatives (PUA), which in turn provides the inductive basis for

the following New Induction over the History of Science: that we have, throughout the history of scientific inquiry and in virtually every field, repeatedly occupied an epistemic position in which we could conceive of only one or a few theories that were wellconfirmed by the available evidence, while subsequent history of inquiry has routinely (if not invariably) revealed further, radically distinct alternatives as well-confirmed by the previously available evidence as those we were inclined to accept on the strength of that evidence (emphasis added).

As K. Brad Wray (2018, p. 82) points out, "Stanford's argument, unlike the reductio ad absurdum attributed to Laudan, is a genuine inductive argument" (emphasis added; see also Wray 2015, p. 68). Again, as Stanford (2006, p. 45) himself puts it, "The new induction provides a pure and simple inductive argument for the claim that we have repeatedly and characteristically occupied a significant underdetermination predicament, failing even to conceive of theoretical alternatives well confirmed by the available evidence that would later be embraced by actual scientists and scientific communities" (emphasis added).

Stanford's New Induction over the History of Science can be reconstructed as follows (Magnus 2010, p. 807): 
A New Induction over the History of Science (NIS)

NIS-1 The historical record reveals that past scientists typically failed to conceive of alternatives to their favorite, then-successful theories.

NIS-2 So, present scientists fail to conceive of alternatives to their favorite, nowsuccessful theories.

NIS-3 Therefore, we should not believe our best present (scientific) theories insofar as they are the result of eliminative inference. ${ }^{1}$

Now, I (Mizrahi 2014; 2016a) have argued that a problem parallel to the PUA applies to the history of Western Philosophy, namely, the Problem of Unconceived Objections (PUO). Consequently, if Stanford's NIS is a cogent inductive argument, then the following is a cogent inductive argument as well:

A New Induction over the History of Philosophy (NIP)

NIP-1 The historical record reveals that past philosophers typically failed to conceive of serious objections to their favorite, then-defensible theories.

NIP-2 So, present philosophers fail to conceive of serious objections to their favorite, now-defensible theories.

NIP-3 Therefore, we should not believe our best present (philosophical) theories insofar as [their defensibility is due in part to serious objections being unconceived]. (Mizrahi 2016a, p. 62)

Given the parallels between Stanford's PUA and the PUO, and those between Stanford's NIS and the NIP, I have sketched the following reductio against Stanford's NIS (Mizrahi 2016a, pp. 63-64):

(1) Stanford's NIS is a cogent argument against scientific realism. [Assumption for reductio]

(2) If Stanford's NIS is a cogent argument against scientific realism, then the NIP is a cogent argument against philosophical realism.

(3) The NIP is a cogent argument against philosophical realism. [from (1) \& (2)]

(4) If the NIP is a cogent argument against philosophical realism, then, if scientific antirealism is a philosophical theory, we should not believe it.

(5) If scientific antirealism is a philosophical theory, we should not believe it. [from (3) \& (4)]

(6) Scientific antirealism is a scientific theory.

(7) We should not believe scientific antirealism. [from (5) \& (6)]

If this reductio is sound, then it clearly poses a problem for the "Stanfordite," to borrow Greg Frost-Arnold's (2016) term. For the Stanfordite surely accepts the PUA and the NIS as a cogent argument against scientific realism. Yet, this very argument against scientific realism has the following (absurd) consequence: that we should not believe scientific antirealism. Clearly, this is

\footnotetext{
${ }^{1}$ Inductive arguments from a sample, such as the NIS, are strong just in case they are based on representative, random samples; otherwise, they are fallacious. See Mizrahi (2015).
} 
a consequence of the PUA and the NIS that the Stanfordite cannot accept, since the Stanfordite is a scientific antirealist insofar as he thinks that we should not believe our best present scientific theories (see NIS-3). ${ }^{2}$

Now, Fabio Sterpetti (2018) seeks to defend Stanford's NIS from my reductio, but he misconstrues my argument against Stanford's NIS. In what follows, I will address this misconstrual of my argument against Stanford's NIS. I will argue that antirealists who endorse Stanford's NIS still face the following absurd consequence of this argument (reductio, not a dilemma): that, by their own lights, they should not believe their own brand of scientific antirealism.

\section{Setting the record straight: reductio vs. dilemma}

Sterpetti (2018) seeks to defend Stanford's NIS from my reductio, but he misconstrues my argument against Stanford's NIS. According to Sterpetti (2018, pp. 4-5):

Mizrahi (2016[a]) develops an argument against Stanford's Position (SP), according to which, if (1) one assumes that Stanford's argument against scientific realism is a cogent argument, and (2) it is possible to adopt Stanford's own line of reasoning in the field of philosophy, then one finds oneself trapped into a dilemma. Indeed, either (a) SP is a scientific position, or (b) SP is not a scientific position, i.e., it is a philosophical position. According to Mizrahi, whichever horn of the dilemma one takes, one should not trust SP in the light of Stanford's own line of reasoning (emphasis in original).

There are a few problems with the way in which Sterpetti has presented my argument against Stanford's NIS. First, he does not say what SP is exactly, but I think he equates it with something that he later labels (SA), namely, "Scientific realism is not true, thus scientific theories are not (approximately) true" (Sterpetti 2018, p. 5). He then claims that my "reconstruction of SA is, to say the least, quite unfair" (Sterpetti 2018, p. 5).

Contrary to what Sterpetti seems to think, however, I do not take Stanford's brand of scientific antirealism to be something like (SA). ${ }^{3}$ In fact, I explicitly say that I take scientific antirealism on the epistemological dimension to be the following thesis (Mizrahi 2016a, p. 65):

(AR) We should not believe that present scientific theories are approximately true.

Again, the conclusion of Stanford's NIS is that we should not believe our best present (scientific) theories (see NIS-3). Along these lines, then, philosophical antirealism, for present purposes, is the view that we should not believe our present philosophical theories. My reductio against Stanford's NIS, then, purports to show that, from the assumption that Stanford's NIS is a cogent argument against scientific realism, it follows that we should not believe (AR).

\footnotetext{
${ }^{2}$ As an anonymous reviewer helpfully pointed out, there are some affinities between this reductio and paradoxes of self-reference in philosophy of logic, such as liar sentences and the like. See, e.g., Russell (1906).

${ }^{3}$ Sterpetti (2018, p. 5) refers to (SA) as a claim. Strictly speaking, however, (SA) is not a claim or a thesis. Rather, it is an argument as the indicator word "thus" indicates. That is, (SA) contains two claims, "scientific realism is not true" and "scientific theories are not (approximately) true," and the conclusion indicator "thus" suggests that the latter is supposed to follow from the former.
} 
Second, contrary to what Sterpetti (2018, p. 5) seems to think, my argument against Stanford's NIS is a reductio, not a dilemma. This is made clear in my (2016a) by the following:

- I explicitly say that my argument against Stanford's NIS is a reductio (Mizrahi 2016a, p. 59, p. 63).

- The main section of the paper Sterpetti engages with is titled "A reductio against Stanford's New Induction on the History of Science" (Mizrahi 2016a, p. 63).

- The dilemma Sterpetti refers to is discussed in the "Objections and Replies" section of the paper as a reply to a potential objection to premise (6) of my reductio, not the main argument of the paper.

Accordingly, the problem that my reductio poses for the Stanfordite is not that he has to choose between two equally undesirable options (the two horns of a dilemma), but rather that he has to deal with an absurd consequence of his own argument against scientific realism, namely, that his own argument entails that he should not believe his own brand of scientific antirealism. As I put it in the paper, "scientific antirealists who endorse Stanford's New Induction on the History of Science cannot accept (7), since (7) says that they should not believe their own position" (Mizrahi 2016a, p. 64).

Third, Sterpetti (2018, p. 4) seems to think that the following is a step in my argument against Stanford's NIS: "it is possible to adopt Stanford's own line of reasoning in the field of philosophy." But this is mistaken. The issue is not whether it is possible to construct an inductive argument over the history of philosophy along the lines of Stanford's NIS. Rather, the point is that the Stanfordite must grant that such an argument applies to the history of philosophy just as it applies to the history of science. Recall that the rationale for the NIS, as Stanford (2006, p. 19) himself says, is the PUA. But the PUA applies to philosophy as well, in the form of the PUO. That is:

In much the same way that "the history of scientific inquiry itself offers a straightforward rationale for thinking that there typically are alternatives to our best theories equally well confirmed by the evidence, even when we are unable to conceive of them at the time" (Stanford 2006, p. 20), the history of philosophical inquiry offers a straightforward rationale for thinking that there typically are serious objections to our best philosophical theories, even when we are unable to conceive of them at the time (Mizrahi 2014, p. 426; emphasis in original). ${ }^{4}$

Since "the PUO is just the PUA applied to philosophy rather than to science" (Mizrahi 2014, p. 428), it follows that, if a Stanfordian new induction over the history of science is a cogent inductive argument, then a parallel new induction over the history of philosophy is a cogent inductive argument as well. Indeed, Stanford himself sometimes puts the PUA and the NIS in general terms that can be applied to both science and philosophy. For instance, according to Stanford (2006, p. 44):

\footnotetext{
${ }^{4}$ See also Mizrahi (2016a, pp. 61-62) and Mizrahi (2016b).
} 
the problem of unconceived alternatives and the new induction suggest not that present theories are no more likely to be true than past theories have turned out to be, but instead that present theorists are no better able to exhaust the space of serious, well-confirmed possible theoretical explanations of the phenomena than past theories have turned out to be (emphasis added).

Of course, insofar as philosophers are also theorists, the PUA applies to them as well. That is, philosophers, too, are no better able to exhaust the space of serious, well-defended possible theoretical explanations of the phenomena than past philosophers have turned out to be. For these reasons, a Stanfordite who endorses the PUA and the NIS is thereby committed to the PUO and the NIP as well. Given that the conclusion of the NIP is that we should not believe our present philosophical theories, the Stanfordite finds himself in the absurd position of having to say that, by his own lights, he should not believe his own philosophical theory about science.

For this reason, it is not clear to me why Sterpetti (2018, p. 13) thinks that my argument against Stanford's NIS (properly understood as a reductio) is "unfair" to Stanford (2006). Sterpetti (2018, p. 13) claims that

By developing [the NIP], Mizrahi (quite unfairly) tries to equate Stanford's scientific anti-realism, which is a sophisticated and well developed philosophical position [...] with a not well developed metaphilosophical position, labeled 'philosophical anti-realism'.

But he does not say why my reductio argument against Stanford's NIS is "quite unfair." Nor does he say why (and in what respects) Stanford's brand of scientific antirealism is a more sophisticated and well developed position than a parallel sort of antirealism applied to philosophy. Of course, I neither defend nor endorse philosophical antirealism, or philosophical realism for that matter, as Sterpetti (2018, p. 15) erroneously thinks, which is why Section 4, titled "A Stanford-Like Argument Against Mizrahi's 'Philosophical Realism'," and Section 5, titled "What if One Accepts Mizrahi's Argument?" of his paper are red herrings. After all, my (2016a) is about the scientific realism debate, specifically Stanford's PUA and the NIS, not metaphilosophy. Indeed, it looks like Sterpetti $(2018$, p. 20) himself suspected as much, for he says that it could be that I simply see philosophical realism "just as a part of the argumentative strategy that [I] develop against Stanford's [NIS]."

Likewise, contrary to what Sterpetti (2018, p. 13) seems to think, I (Mizrahi 2016a, pp. 63-64) neither endorse nor am committed to the NIP. Sterpetti (2018, p. 13) claims that

The problem is that Mizrahi's argument against Stanford's [NIS] crucially relies on [the NIP]. Now, it is [the NIP] which is a blatantly self-defeating argument [...]. Indeed, if one maintains [the NIP], one is clearly advocating for a philosophical position, i.e. one is committing oneself to a given philosophical theory, namely the philosophical theory

\footnotetext{
${ }^{5}$ Sterpetti (2018, p. 13) seems to have misinterpreted philosophical antirealism as well, for he writes that philosophical antirealism is the view "according to which philosophical theories are not true, simpliciter." This is mistaken. Philosophical antirealism is a view parallel to scientific antirealism. Given that scientific antirealism is the view that we should not believe that our present scientific theories are true, philosophical antirealism is the view that we should not believe that our present philosophical theories are true.
} 
according to which we should not believe philosophical theories. But according to [the NIP] itself, we should not trust philosophical theories, so, [the NIP] is self-defeating.

Sterpetti erroneously thinks that I am committed to the NIP because he has misconstrued my argument against Stanford's NIS. As mentioned above, my argument against Stanford's NIS is a reductio, not a dilemma, as Sterpetti (2018, p. 15) erroneously thinks. Once this confusion is cleared up, it becomes clear that I am not committed to the NIP. The NIP follows from the assumption (for reductio) that Stanford's NIS is a cogent argument against scientific realism (see steps 1-3 of the reductio outlined in Section 1). Clearly, when one advances a reductio against $p$, one is not thereby committed to all the unacceptable or absurd consequences that follow from assuming that $p$ is true (Marcus 2018, pp. 185-186). Just as Sterpetti (2018, p. 11) is not committed to what he takes to be the absurd consequences that follow from assuming what he wants to argue against by reductio, namely, from assuming that scientific realism is true, I am not committed to what I take to be the absurd consequences that follow from assuming what I want to argue against by reductio, namely, from assuming that Stanford's NIS is a cogent argument against scientific realism. ${ }^{6}$ My reductio against Stanford's NIS, if sound, shows that the assumption that Stanford's NIS is a cogent argument against scientific realism has the consequence that NIP is a cogent argument against philosophical realism. Since the Stanfordite endorses the NIS as a cogent argument against scientific realism, he must grant that the NIP is a cogent argument against philosophical realism. But this leads to a consequence that the Stanfordite cannot accept, namely, that he should not believe his own brand of scientific antirealism. Clearly, this is an absurd position for a scientific antirealist like the Stanfordite to be in. ${ }^{7}$

In that respect, it is important to point out that, as I have argued elsewhere, historical inductions, both old, such as Larry Laudan's pessimistic induction (Mizrahi 2013a), and new, such as Stanford's NIS (Mizrahi 2015), are weak inductive arguments. The problems with these historical inductions are that they tend to commit the fallacy of biased statistics (Park 2011), they are based on unrepresentative samples (Fahrbach 2011), and the inductive samples they are based on are typically cherry-picked rather than randomly selected (Mizrahi 2013a). So, unless these historical inductions can be improved significantly by following stricter procedures of random sampling and inductive reasoning (see Mizrahi 2016b; 2016c), I would not endorse such inductive arguments, whether the induction is over the history of science or the history of philosophy.

\footnotetext{
${ }^{6}$ According to Sterpetti (2018, p. 16), his reductio "arguments are not self-defeating arguments, they are arguments that merely point out that if one supports realism, then one should be able to face the objection conveyed by those arguments." If Sterpetti is right about this point, then it should apply to my reductio as well, of course. My reductio against Stanford's NIS is not self-defeating, as Sterpetti erroneously thinks, for it points out that, if one supports Stanford's NIS, then one should face the objection conveyed by the PUO.

${ }^{7}$ At one point, Sterpetti (2018, p. 6) gets this right when he writes, "if one accepts Stanford's argument against scientific realism, one has to accept Mizrahi's Stanford-like argument for the field of philosophy as well.” Clearly, I do not accept Stanford's NIS; after all, I argue against it. It is equally clear that Stanford accepts his own NIS; after all, it is his own argument against scientific realism. Now, if Stanford accepts his own NIS, which he clearly does, then he must accept the NIP, for, as Sterpetti himself points out, "if one accepts Stanford's [NIS], one has to accept [the NIP] as well"' (Sterpetti 2018, p. 6).
} 
Finally, Sterpetti (2018, p. 5) also misconstrues my argument against Stanford's NIS when he writes, "in Mizrahi's view, since SP is an anti-realist stance, then because of this very fact it is self-defeating." This is mistaken. It is not the mere fact that Stanford's NIS is an argument for scientific antirealism that makes it self-defeating. ${ }^{8}$ Rather, given the parallels between Stanford's PUA and the PUO, as well as those between Stanford's NIS and the NIP, one could run an induction over the history of philosophy that is analogous to Stanford's induction over the history of science. Since the Stanfordite accepts the latter as a cogent argument against scientific realism, he must grant that the former is a cogent argument against philosophical realism as well. Granting that, however, means that he should not believe his own philosophical theory about science, i.e., his own brand of scientific antirealism, by his own lights. ${ }^{9}$

\section{Setting the record straight: inductive vs. deductive arguments}

As mentioned above, Sterpetti (2018, p. 15) thinks that I have misinterpreted Stanford's NIS. Sterpetti claims that Stanford's NIS is not an inductive argument at all. Rather, it is a deductive argument, specifically, "a reductio against scientific realism" (Sterpetti $\left(2018\right.$, p. 6). ${ }^{10}$

There are several problems with Sterpetti's interpretation of Stanford's NIS as a reductio instead of an induction over the history of science. First, it goes against what Stanford himself says about his argument. As mentioned above, Stanford himself characterizes his NIS as an inductive argument. I have presented textual evidence for this in Section 1. Here is another quote from Stanford (2006, p. 19) to that effect:

I suggest that the historical record offers plainspoken inductive testimony to the fact that we have repeatedly occupied a predicament of recurrent, transient underdetermination across a wide and heterogeneous variety of scientific fields and domains of inquiry simply because we have failed to conceive of all the empirically inequivalent but scientifically serious alternative theoretical possibilities well confirmed by the evidence available to us (emphasis added). ${ }^{11}$

Second, it goes against how other philosophers of science have interpreted Stanford's NIS (see, e.g., Magnus 2010, Wray 2015, and Park 2018, pp. 68-70). But perhaps these philosophers of science, and even Stanford himself, are wrong. Perhaps Sterpetti is right that Stanford's NIS should be construed as a deductive (specifically, a reductio), not an inductive, argument.

\footnotetext{
${ }^{8}$ In fact, I point out in a footnote (Mizrahi 2016a, p. 64, footnote 2) that, "for this reductio to go through, there is no need to assume that Stanford's [NIS] is an argument for antirealism (in particular, his own brand of antirealism, namely, "epistemic instrumentalism"). All that needs to be assumed is that, at the very least, Stanford's [NIS] is supposed to be an argument against scientific realism" (emphasis in original).

${ }^{9}$ Sterpetti (2018, p. 21) claims that "the great majority of philosophers does not think that philosophical theories are true in the same sense in which scientific theories are true," but he does not explain these different senses of truth. Nor does he provide any evidence in support of this claim about what most philosophers think.

${ }^{10}$ After he says that "Stanford's argument can be reconstructed as a reductio against scientific realism" (Sterpetti 2018, p. 8), Sterpetti goes on to give another "formulation of the problem of unconceived alternatives [which] is not inductive in character," but is not a reductio (Sterpetti 2018, p. 9). It is not clear to me if he sees these two formulations as equivalent, related, or neither.

${ }^{11}$ See also Stanford (2017).
} 
I do not think so. The reason is that there is no clear payoff for doing so. Of course, any inductive argument can be turned into a deductive argument with the addition of suitable premises. For example, the following is an inductive argument:

Past scientists typically have been men.

Therefore, this scientist is a man.

This is an inductive argument because the premise is not supposed to provide conclusive support for the conclusion. Rather, the premise, if true, is supposed to render the conclusion more probable or likely to be true. Like any argument, one could ask whether the premise, if true, really would make the conclusion more probable or likely to be true. In this case, one would be concerned with the strength of the inference from the premise to the conclusion. One could also ask whether the premise is in fact true. In that case, one would be concerned with the cogency of the argument.

Now, this inductive argument can easily be turned into a deductive argument by adding a premise that would make the conclusion follow necessarily from the premises.

If past scientists typically have been men, then this scientist is a man.

Past scientists typically have been men.

Therefore, this scientist is a man.

Now this argument is deductive, in particular, it takes the logical form modus ponens. But what have we gained by turning this argument from an inductive into a deductive argument? Nothing, it seems, for we still have to deal with the same questions, only now we are concerned with the truth of the premises rather than the strength of the inference. That is, as far as the inductive version of the argument is concerned, we want to know if the truth of "past scientists typically have been men" really does make it more likely that "this scientist is a man" is true. As far as the deductive version of the argument is concerned, we want to know whether "if past scientists typically have been men, then this scientist is a man" is in fact true. Although our focus has shifted from examining the strength of the inference to examining the truth of the premises, it is not clear that we have gained anything, as far as deciding whether we should accept the conclusion of the argument, by doing so. Anyone who is not inclined to accept the conclusion of the inductive version of the argument is unlikely to be convinced by the deductive version of the argument, either.

This point applies to Sterpetti's attempt to reinterpret Stanford's NIS as a deductive argument (specifically, a reductio). As far as the inductive version of Stanford's NIS is concerned, we want to know whether the inference from NIS-1 to NIS-2 is strong. That is, assuming, for the sake of argument, that the historical record really does show that past scientists typically failed to conceive of alternatives to their favorite, then-successful theories, does that make it more likely that present scientists fail to conceive of alternatives to their favorite, nowsuccessful theories? ${ }^{12}$ As far as Sterpetti's deductive version of Stanford's NIS, our focus shifts from examining the strength of the inference to examining the truth of the premises. The

\footnotetext{
${ }^{12}$ For more on this question, see Mizrahi (2015).
} 
premises in Sterpetti's (2018, p. 11) reconstruction of Stanford's NIS as a reductio are the following:

Premise 1: "History of science shows that scientific theories routinely changed at time $t+$ $1(\neg$ a) in ways that might had been conceived by scientists at time $t$, but scientists routinely failed to conceive at time $t(\neg \mathrm{b})$."

Premise 2: "We do not have reasons to claim that cognitive abilities of current scientists changed so that they are now able to conceive all the possible alternatives to a given theory $\mathrm{T}$ at time $t$, and so that they cannot fail to know whether $\mathrm{T}$ is true at time $t$, and whether $\mathrm{T}$ is going to change at time $t+1 . "$

Premise 3: "[Premise 1] and [Premise 2] are observed patterns that can be theoretically explained as follows: we have reason to believe that $\mathrm{T}$ has unconceived alternatives, unless we are able to prove that $\mathrm{T}$ has no unconceived alternatives. Since providing reason to believe that $\mathrm{T}$ has no unconceived alternatives is impossible, we are not able to know whether $\mathrm{T}$ is true at time $t$, and whether $\mathrm{T}$ is going to change at time $t+1$."

There is a lot to unpack here and my space is limited. But it should be clear that these premises are far from being obviously true. As far as Premise 1 is concerned, it is far from obvious that, in general, scientific theories routinely change. Some scientific theories and theoretical posits are quite stable and have been around for more than two centuries (Mizrahi 2016c). Also, how much does a scientific theory have to change such that it becomes difficult (impossible?) to conceive at a particular point in time?

As far as Premise 2 is concerned, it is far from obvious that scientists must be "able to conceive of all the possible alternatives to a given theory T" (Sterpetti 2018, p. 11) before they can be confident that the theory counts as scientific knowledge. Sterpetti seems to be making a few unreasonable assumptions about scientific knowledge here. ${ }^{13}$ Sterpetti seems to think that the alternatives in the PUA refer to logical possibilities. On Sterpetti's view, then, in order to know that there is something like dark energy, say, I have to eliminate all logical possibilities, including the one according to which "the universe is accelerating because God is blowing wind on galaxies" (Mizrahi 2016a, p. 62). As I explain in that same paper, however, unconceived alternatives are not mere logical possibilities (Mizrahi 2016a, p. 62). To equate unconceived alternatives with mere logical possibilities, as Sterpetti does, is to turn Stanford's PUA "from a probability claim, which is supposed to be backed up by the historical record, to a mere possibility claim, and thus [Stanford's NIS] becomes a conceivability argument about what is merely possible rather than an inductive argument about what is probable" (Mizrahi 2015, p. 144). The problem with that, of course, is that, just as it is logically possible that $p$, it is equally logically possible that not $p$. Indeed, Stanford himself says that an unconceived alternative is not merely a logical possibility, but rather a competing theory that is "well confirmed by the body of actual evidence we have in hand" (Stanford 2006, p. 18). That is why "the hypothesis that the

\footnotetext{
13 Throughout his paper, Sterpetti (2018) frequently uses terms and phrases like "prove” (p. 10), “certainty" (p. 7), "know with certainty" (p. 9), and the like. This suggests that he might have unreasonably high standards for not only scientific knowledge but also knowledge in general. For once one demands certainty as a requirement for knowledge, many claims to knowledge, not only scientific ones, fall into question.
} 
universe is accelerating because God is blowing wind on galaxies is not an unconceived alternative to the dark energy hypothesis because it is not confirmed (let alone well confirmed) by the body of actual evidence we have in hand" (Mizrahi 2015, p. 138). On the other hand, "the Tychonic system was an empirically viable alternative, not merely a logical possibility, and hence a serious contender and a serious objection to the heliocentric model" (Mizrahi 2016a, p. $62)$.

As far as Premise 3 is concerned, once the confusion about unconceived alternatives is cleared up, it is far from obvious that there are always reasons to think that, for any theory $\mathrm{T}$, there are always unconceived "equally well-confirmed and scientifically serious alternatives" (Stanford 2006, p. 44). Excluding mere logical possibilities, how many "equally well-confirmed and scientifically serious alternatives" (Stanford 2006, p. 44) are there to theories of inheritance, or electricity, or magnetism? A few (Mizrahi 2015), but certainly not so many as to make it impossible to justifiably believe (though not "prove" in the strict sense, as Sterpetti seems to demand) that T has no "equally well-confirmed and scientifically serious alternatives" (Stanford 2006, p. 44). ${ }^{14}$

In light of the above, then, it is not clear what Sterpetti has gained from turning Stanford's NIS from an inductive argument over the history of science to a deductive argument (specifically, a reductio). Instead of asking questions about the strength of the inference, we would simply be asking questions about the truth of the premises. At bottom, however, these questions are basically the same sort of questions; that is, questions about the lessons we should draw from the historical record of science. Consequently, even if "criticisms based on the weakness of inductive inferences can be avoided by Stanford" (Sterpetti 2018, p. 12), if Sterpetti is right that Stanford's NIS should be construed as a deductive argument, these criticisms would simply be recast as criticisms directed against the premises instead of the inference.

\section{Conclusion}

After setting the record straight regarding Stanford's NIS (it is an inductive, not a deductive, argument), my argument against Stanford's NIS (it is a reductio, not a dilemma), I would like to make one more clarification in closing. Sterpetti concludes his (2018) by claiming that I have failed in "defend[ing] philosophical realism" and in "supporting scientific realism" (Sterpetti 2018 , p. 21). ${ }^{15}$ This is not surprising, of course, because the aim of my (2016a) is neither to defend philosophical realism nor to support scientific realism. As mentioned above, philosophical antirealism (i.e., the view that we should not believe our present philosophical theories) is simply a position parallel to scientific antirealism (i.e., the view that we should not believe our present scientific theories) that I use as an argumentative device in my reductio argument against Stanford's NIS. In my (2016a), I neither defend it nor am I committed to it.

\footnotetext{
${ }^{14}$ Like Stanford (2006), Rowbottom (2016), which Sterpetti (2018) cites with approval, also uses the term "serious" when talking about unconceived alternatives. In that respect, it should also be noted that, to Rowbottom's list of unconceived things, like observations and models, one could easily add objections, as in the PUO (Mizrahi 2014; 2016a).

${ }^{15}$ Sterpetti (2018, p. 20) claims that, "if one regards [Mizrahi's reductio against Stanford's NIS] as a cogent argument, one cannot avoid committing oneself to 'philosophical realism'." But I do not see how a commitment to philosophical realism is supposed to follow from my reductio against Stanford's NIS and Sterpetti does not explain how or why he thinks that.
} 
Moreover, I am not a scientific realist, either, and I do not attempt to defend or support scientific realism in my (2016a). In fact, I say so explicitly: "my aim in this paper is not to defend scientific realism, but rather to expose what I take to be problems with Stanford's [NIS]" (Mizrahi 2016a, p. 66). Sterpetti must have assumed that, if I argue against scientific antirealism, I must be a scientific realist. But this is a false dichotomy, if only because there are numerous versions of scientific realism, as well as views in between scientific realism and antirealism, in the literature. ${ }^{16}$ Indeed, I take my own view to be a middle-ground position between scientific realism and antirealism because "it acknowledges the antirealist's point that theory evaluation is comparative while, at the same time, retaining the realist's optimism about science's ability to get closer to the truth" (Mizrahi 2013b, p. 402).

\section{Acknowledgments}

I would like to thank two anonymous reviewers of Axiomathes for their helpful comments.

\section{References}

Chakravartty, A. (2017). Scientific Realism. In Edward N. Zalta (ed.), The Stanford Encyclopedia of Philosophy (Summer 2017 Edition). https://plato.stanford.edu/archives/sum2017/entries/scientific-realism/.

Fahrbach, L. (2011). How the Growth of Science Ends Theory Change. Synthese 180 (2): 139155.

Frost-Arnold, G. (2016). Should a Historically Motivated Anti-realist be a Stanfordite? Synthese. https://doi.org/10.1007/s11229-016-1050-z.

Magnus, P. D. (2010). Inductions, Red Herrings, and the Best Explanations for the Mixed

Record of Science. British Journal for the Philosophy of Science 61 (4): 803-819.

Marcus, R. (2018). Introduction to Formal Logic with Philosophical Applications. New York: Oxford University Press.

Mizrahi, M. (2013a). The Pessimistic Induction: A Bad Argument Gone Too Far. Synthese 190 (15): 3209-3226.

Mizrahi, M. (2013b). The Argument from Underconsideration and Relative Realism. International Studies in the Philosophy of Science 27 (4): 393-407.

Mizrahi, M. (2014). The Problem of Unconceived Objections. Argumentation 28 (4): 425-436.

Mizrahi, M. (2015). Historical Inductions: New Cherries, Same Old Cherry-picking. International Studies in the Philosophy of Science 29 (2): 129-148.

\footnotetext{
${ }^{16}$ For an overview, see Chakravartty (2017).
} 
Mizrahi, M. (2016a). Historical Inductions, Unconceived Alternatives, and Unconceived Objections. Journal for General Philosophy of Science 47 (1): 59-68.

Mizrahi, M. (2016b). Why Be an Intellectually Humble Philosopher? Axiomathes 26 (2): 205218.

Mizrahi, M. (2016c). The History of Science as a Graveyard of Theories: A Philosophers' Myth? International Studies in the Philosophy of Science 30 (3): 263-278.

Park, S. (2011). A Confutation of the Pessimistic Induction. Journal for General Philosophy of Science 42 (1): 75-84.

Park, S. (2018). Can Kuhn's Taxonomic Incommensurability Be an Image of Science? In M. Mizrahi (ed.), The Kuhnian Image of Science: Time for a Decisive Transformation? (pp. 61-74). Lanham, MA: Rowman \& Littlefield.

Rowbottom, D. P. (2016). Extending the Argument from Unconceived Alternatives: Observations, Models, Predictions, Explanations, Methods, Instruments, Experiments, and Values. Synthese. https://doi.org/10.1007/s11229-016-1132-y.

Russell, B. (1906). On Some Difficulties in the Theory of Transfinite Numbers and Order Types. Proceedings of the London Mathematical Society 4 (14): 29-53.

Stanford, P. K. (2001). Refusing the Devil's Bargain: What Kind of Underdetermination Should We take Seriously? Philosophy of Science 68 (Proceedings): S1-S12.

Stanford, P. K. (2006). Exceeding Our Grasp: Science, History, and the Problem of Unconceived Alternatives. New York: Oxford University Press.

Stanford, P. K. (2017). Underdetermination of Scientific Theory. In Edward N. Zalta (ed.), The Stanford Encyclopedia of Philosophy (Winter 2017 Edition). https://plato.stanford.edu/archives/win2017/entries/scientific-underdetermination/.

Sterpetti. F. (2018). On Mizrahi's Argument against Stanford's Instrumentalism. Axiomathes. https://doi.org/10.1007/s10516-018-9392-4.

Wray, K. B. (2015). Pessimistic Inductions: Four Varieties. International Studies in the Philosophy of Science 29 (1): 61-73.

Wray, K. B. (2018). Resisting Scientific Realism. New York: Cambridge University Press. 